\title{
Synthesis and Characterization of Nitrido(tetra-tert-butylphthalocyaninato)- rhenium(V) and Nitrido(phthalocyaninato)rhenium(V)
}

\author{
Ulrich Ziener and Michael Hanack* \\ Institut für Organische Chemie, Lehrstuhl für Organische Chemie II, Universität Tübingen, \\ Auf der Morgenstelle 18, 72076 Tübingen, Germany
}

Received March 2, 1994

Key Words: Rhenium(V), nitrido(tetra-tert-butylphthalocyaninato)- / Rhenium(V), nitrido(phthalocyaninato)- / Phthalocyaninato complexes

4-tert-Butylphthalodinitrile (1) reacts with ammonium perrhenate, $\mathrm{NH}_{4} \mathrm{ReO}_{4}$, to yield nitrido(tetra-tert-butylphthalocyaninato)rhenium $(\mathrm{V}),(t \mathrm{Bu})_{4} \mathrm{PcReN}(2)$, which is characterized by $\mathrm{IR}_{1}$ UV/Vis, CV, MS, ${ }^{1} \mathrm{H}$ and ${ }^{13} \mathrm{C}$ NMR, and elemental analysis. It shows good solubility in common organic solvents. In solution 2 is assumed to be monomeric whereas in the solid state also dimers or higher aggregates are present. From the NMR spectra it is concluded that different constitutional isomers of $\mathbf{2}$ are formed but not in the expected ratio of a statistical distribution. By analogy with 2, the already known nitrido(phthalocyaninato)rhenium(V), PcReN (3), is prepared for comparison.
Our ongoing work is concerned with bridged macrocyclic phthalocyaninato transition metal complexes $[\mathrm{PcM}(\mathrm{L})]_{n}$ (with $\mathrm{M}$ e.g. $\mathrm{Fe}, \mathrm{Ru}, \mathrm{Os}$ ) that contain the ligands $\mathrm{L}$ as bidentate linear organic molecules, e.g. pyz (pyrazine), tz (tetrazine), dib (1,4-diisocyanobenzene), leading to a comparable large distance $(600-1200 \mathrm{pm})$ between the cofacial $\mathrm{Pc}$ rings in the polymer ${ }^{[1]}$. A smaller distance of the macrocycles in such polymers could be advantageous, e.g. for the electrical properties. Oxygen as the bridging ligand which could lead to a smaller distance between the macrocyclic units is only known for one example in the hemiporphyrazine $(\mathrm{Hp})$ compound $[\mathrm{HpFeO}]_{n}$ with $\mathrm{Fe}^{+\mathrm{IV}}$ as the central metal ion ${ }^{[2]}$. PcFe does not form an equivalent compound but $\mu$-oxo dimers $(\mathrm{PcFe})_{2} \mathrm{O}^{[3]}$. Therefore we investigated the possibility of using nitrogen as a potential candidate for a bridging ligand.

Nitride, $\mathrm{N}^{3-}$, is known as one of the strongest $\pi$-donor ligands ${ }^{[4]}$. Several nitrido metal complexes of porphyrins, e.g. TPPMnN ${ }^{[4,5]}$ or OEPReN ${ }^{[6]}$, have been prepared. However, only few corresponding complexes with phthalocyanines are known, namely $\mathrm{PcMnN}^{[7]}, \mathrm{PcTcN}^{[8]}, \mathrm{PcReN}$ $(3)^{[9]}$, and the dinuclear complexes $(\mathrm{PcFe})_{2} \mathrm{~N}^{[10]}$ and $(\mathrm{PcRu})_{2} \mathrm{~N}^{[11]}$. Especially the heavier transition metal ions in high oxidation states are suitable for forming the $\mathrm{M}-\mathrm{N}$ triple bond. The nitrido(phthalocyaninato) complexes are all quite insoluble in common organic solvents.

In this paper we report on the synthesis of the first soluble nitrido(phthalocyaninato)rhenium complex, nitrido(tetra-tert-butylphthalocyaninato)rhenium, $(t \mathrm{Bu})_{4} \mathrm{PcReN}$ (2). For comparison the synthesis of PcReN (3) was repeated ${ }^{[9]}$. Up to now the bonding conditions of the axial $\mathrm{Re}-\mathrm{N}$ bond in both 2 and 3 are not completely clear. Asymmetric bridging as known for example in $\mathrm{K}_{2} \mathrm{ReN}(\mathrm{CN})_{4} \cdot \mathrm{H}_{2} \mathrm{O}^{[12]}$ cannot be excluded.

\section{Results and Discussion}

Nitrido(tetra-tert-butylphthalocyaninato)rhenium(V), $(t \mathrm{Bu})_{4} \mathrm{PcReN}(2)$, was synthesized by reaction of 4-tert-butylphthalodinitrile (1) with ammonium perrhenate (see Scheme 1).

Scheme 1. a) Synthesis and b) structure of $(t \mathrm{Bu})_{4} \mathrm{PcReN}(2)\left(C_{4 h}\right.$ isomer)

a)

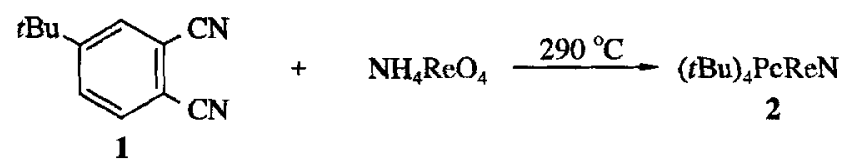

b)

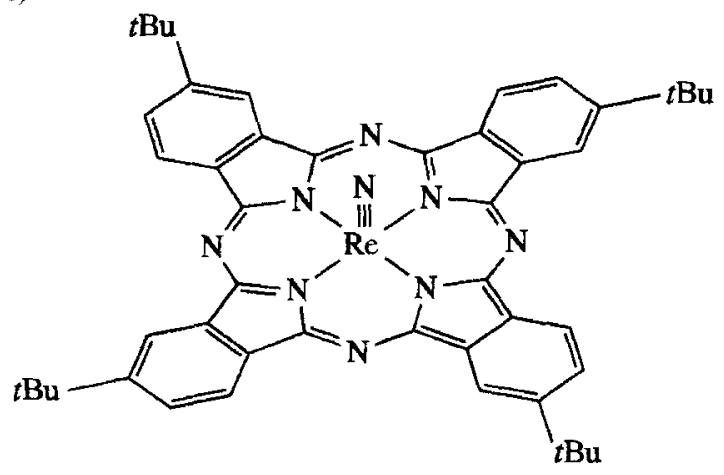

Compound 2 was purified by column chromatography; its yield is low compared to that of PcReN (3) (see below).

The IR spectrum of $\mathbf{2}$ is very similar to those of other tetra-tert-butyl-substituted phthalocyaninato metal complexes such as $(t \mathrm{Bu})_{4} \mathrm{PcCo}^{[13]}$ and $(t \mathrm{Bu})_{4} \mathrm{PcFe}^{[14]}$. In the region between 950 and $1000 \mathrm{~cm}^{-1}$ a band of low intensity is found in all these IR spectra. In the spectrum of $\mathbf{2}$ the intensity of this band at $978 \mathrm{~cm}^{-1}$ is somewhat increased. This 
increase is assigned to the $\mathrm{Re}-\mathrm{N}$ triple bond vibration as it is in the expected region of metal $-\mathrm{N}$ triple bond vibrations ${ }^{[4]}$. Besides, this band is in agreement with the one at $978 \mathrm{~cm}^{-1}$ reported for $\operatorname{PcReN}(\mathbf{3})^{[9]}$ (see below).

The UV/Vis spectrum of 2 in $\mathrm{CH}_{2} \mathrm{Cl}_{2}$ is similar to that of e.g. $(t \mathrm{Bu})_{4} \mathrm{PcCu}^{[15]}$ or to those of many other substituted soluble phthalocyaninato metal complexes with the $\mathrm{Q}$ band at $\lambda_{\max }=698 \mathrm{~nm}$ and vibronic transitions at $667,628,603$, and $584 \mathrm{~nm}$. The B band shows two maxima at 363 and $346 \mathrm{~nm}$. Compared to $(t \mathrm{Bu})_{4} \mathrm{PcCu}$, the $\mathrm{Q}$ band is redshifted about $25 \mathrm{~nm}$. This may be caused by the high oxidation state $+V$ of the rhenium in 2 . We have no indication of exciton interaction of dimers or even larger aggregates $^{[16]}$, so that we assume monomeric units of $\mathbf{2}$ in solution. In contrast, the $\mathrm{Q}$ band in a solid-state electronic spectrum appears at $\lambda_{\max }=697 \mathrm{~nm}$ with two shoulders at 669 and about $750 \mathrm{~nm}$. The band at $697 \mathrm{~nm}$ is assigned to the $\pi-\pi^{*}$ transition of monomeric units and the other two bands to exciton interactions of dimeric units ${ }^{[16]}$ with an exciton coupling of about $80 \mathrm{~nm}$ which is lower than that of PcReN (3) of about $150 \mathrm{~nm}$ (see below). This is in agreement with larger distances between neighboring macrocyclic units of $\mathbf{2}$ in the solid state than of $\mathbf{3}$ because of steric hindrance of the tert-butyl groups in 2.

The cyclic voltammogram of $\mathbf{2}$ in $\mathrm{CH}_{2} \mathrm{Cl}_{2}$ (see Figure 1) shows two peaks in the reductive region at -0.527 and $-0.896 \mathrm{~V}$ (vs. SCE) both with a value of $\Delta E_{\mathrm{P}}=88 \mathrm{mV}$. Due to subsequent spectroelectrochemical (SEC) investigations we assign these peaks to the reduction of the metal $\mathrm{Re}^{+V}+\mathrm{e}^{-} \rightarrow \mathrm{Re}^{+I V}$ and of the macrocycle $\left(t \mathrm{Bu}_{4} \mathrm{Pc}^{-\mathrm{II}}+\right.$ $\mathrm{e}^{-} \rightarrow(t \mathrm{Bu})_{4} \mathrm{Pc}^{-\mathrm{III}}$, respectively. Both reactions exhibit two isosbestic points in the SEC measurement. As $\Delta E_{\mathrm{p}}$ is not dependent on the scan rate, one-step reactions with quasireversible electron transitions are present.

In the oxidative region, the $\mathrm{CV}$ measurement exhibits two kinetically irreversible peaks and a shoulder. The shape of the waves was not changed when the potential sweep was initiated in the negative potential direction first. In the corresponding SEC measurements the typical bands of the macrocycle vanish indicating destruction of the complex.

\section{CURRENT $[\mu \mathrm{A}]$}

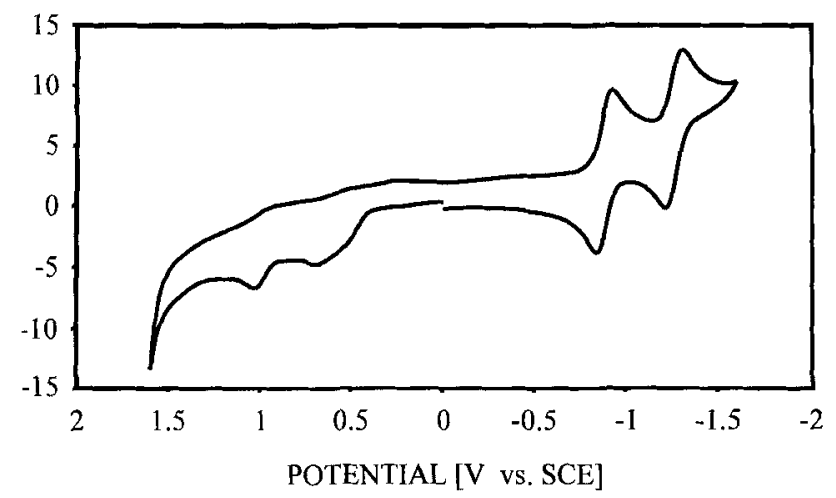

Figure 1. Cyclic voltammogram of $(t \mathrm{Bu})_{4} \mathrm{PcReN}(\boldsymbol{2})$ in $\mathrm{CH}_{2} \mathrm{Cl}_{2}$ $\left(c=8 \cdot 10^{-4} \mathrm{~mol} / 1\right) ;(n \mathrm{Bu})_{4} \mathrm{NPF}_{6} ;$ scan rate: $100 \mathrm{mV} / \mathrm{s}$
A FD/MS spectrum of 2 exhibits the expected peak at $m / z=937.4$ (calculated 937.4) showing the calculated isotope distribution (see Figure 2).

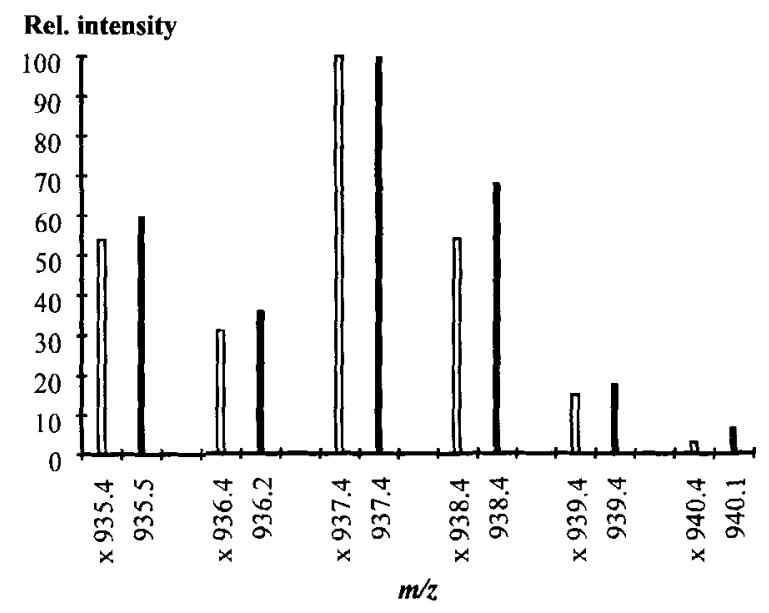

Figure 2. FD mass spectrum (molecular peak region) of $(t \mathrm{Bu})_{4} \mathrm{PcReN}$ (2), measured and calculated (x) isotope distribution

The ${ }^{1} \mathrm{H}$-NMR spectrum of $2(4 \mathrm{mg} / \mathrm{ml})$ in $\mathrm{CDCl}_{3}$ (Figure 3) shows quite a complicated pattern in the aromatic region as expected for four isomers of the tetrasubstituted phthalocyanine complex of symmetry $C_{4 h}, C_{2,}, D_{2 h}$, and $C_{s}$. The additional details obtained from the spectrum are treated by Gaussian multiplication to obtain a better resolution. The splitting pattern of this spectrum differs from that of e. g. $(t \mathrm{Bu})_{4} \mathrm{PcNi}^{[17]}$ measured in benzene. This could be due to the fact that different solvents $\mathrm{CDCl}_{3}$ and $\mathrm{C}_{6} \mathrm{D}_{6}$ were used, the influence of the solvent on the NMR spectrum is not completely clear. Three multiplets in the aromatic region at $\delta=8.39,9.46$, and 9.56 in the proportion 1:1:1 are found for 2 . The first one can be explained by two very narrow doublets $(J=8.2 \mathrm{~Hz})$ at 8.38 and 8.40 which are again split into two doublets $(J=1.8 \mathrm{~Hz})$ with a ratio of intensity of about $6: 1$. They are assigned to $1-\mathrm{H}$ coupling with $2-\mathrm{H}(J=8.2 \mathrm{~Hz})$ and $2^{\prime}-\mathrm{H}(J=1.8 \mathrm{~Hz})$ (Figure 3$)$. The second multiplet is caused by $2-\mathrm{H}$ and the third by $2^{\prime}-$ $H$. For the tert-butyl groups three peaks at $\delta=1.817,1.828$, and 1.835 with a ratio of about $6: 13: 1$ are found. A statistical distribution of the isomers would cause eight peaks with equal intensities as the spectrum of e.g. $(t \mathrm{Bu})_{4} \mathrm{PcNi}$ shows ${ }^{[17]}$. Even if the two peaks at $\delta=1.817$ and 1.828 represented seven of the eight expected peaks, the ratio of these two peaks with respect to the third one should be at most $(6+13): 2.7$ or $7: 1$. Therefore, we suppose that different isomers of 2 are present but that the ratio is not the statistical one, $1: 1: 2: 4\left(D_{2 h}: C_{4 h}: C_{2 v}: C_{s}\right)$. This may be attributed to the influence of the rhenium atom on formation of the phthalocyanine unit.

A ${ }^{13} \mathrm{C}$-NMR spectrum $(40 \mathrm{mg} / \mathrm{ml})$ of 2 in $\mathrm{CDCl}_{3}$ exhibits ten signals which are all split or show at least a shoulder. This is no proof of the presence of all possible isomers because at this high concentration aggregation effects are expected, although aggregation affects ${ }^{13} \mathrm{C}$ - less than ${ }^{1} \mathrm{H}$ NMR spectra ${ }^{[17]}$. If a ${ }^{1} \mathrm{H}-\mathrm{NMR}$ spectrum of 2 with the same concentration $(40 \mathrm{mg} / \mathrm{ml})$ is recorded much more 
peaks both in the aromatic region at $\delta=8.28-8.38$ and $8.36-8.41$, respectively, and in the region of the tert-butyl groups at $\delta=1.85-1.90$ are found than in the case of lower concentration (see above). The high-field shift of the aromatic protons and the low field shift of the tert-butyl protons compared with the spectrum at low concentration (see above) is probably due to aggregation, but the effect is low. Therefore distinction between different isomers and aggregation effects is difficult.

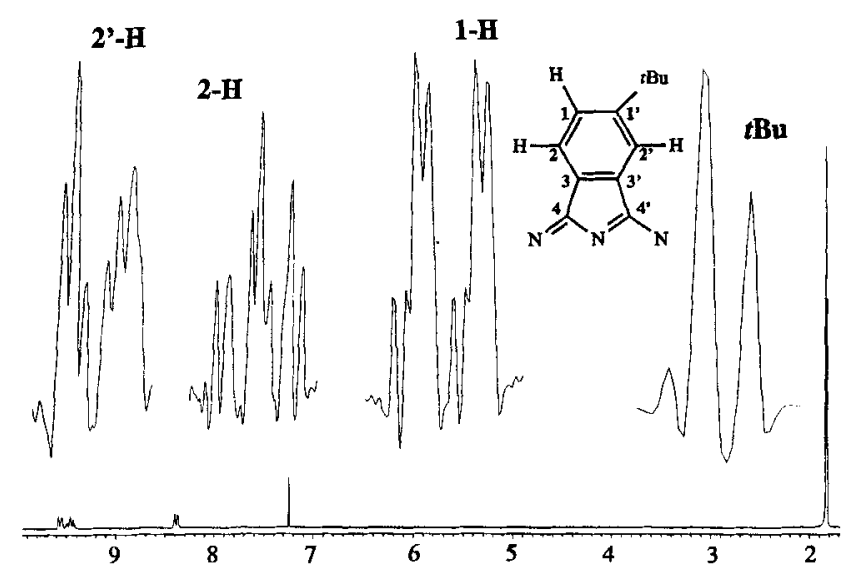

Figure 3. 'H-NMR spectrum of $(t \mathrm{Bu})_{4} \mathrm{PcReN}(2), \delta$ scale

In 1970 the synthesis of the (phthalocyaninato)rhenium sulfate $\mathrm{PcReSO}_{4} \cdot 2 \mathrm{H}_{2} \mathrm{O}$ by reaction of phthalodinitrile with ammonium perrhenate and subsequent purification with sulfuric acid was reported ${ }^{[18]}$. This result was corrected some years later ${ }^{[9]}$. Thus the authors obtained under the same conditions followed by sublimation at room temperature a nitrido(phthalocyaninato)rhenium(V) complex $\mathrm{PcReN}(3)$. We have now repeated this reaction (see Scheme 2 ); the compound 3 obtained was purified by extraction with water, ethanol, and acetone.

Scheme 2<smiles>N#Cc1ccccc1C#N</smiles>$$
+\mathrm{NH}_{4} \mathrm{ReO}_{4} \frac{290^{\circ} \mathrm{C}}{3} \underset{3}{\mathrm{PcReN}}
$$

The IR spectrum of 3 is identical with that reported in ref. ${ }^{[9]}$. It shows mainly the bands which are found in the spectra of the $\alpha$-modification of phthalocyaninato metal complexes, e.g. $\alpha-\mathrm{PcCu}^{[19]}$, and additionally a single strong band at $978 \mathrm{~cm}^{-1}$ which is assigned to the $\mathrm{Re}-\mathrm{N}$ triple bond vibration as found also for $(t \mathrm{Bu})_{4} \operatorname{PcReN}(2)$. In contrast to the literature ${ }^{[9]}$ this band partially vanishes after dissolving 3 in concentrated sulfuric acid and precipitation with $\mathrm{H}_{2} \mathrm{O}$. In the elemental analysis of the product thus obtained some sulfur is found but not enough as calculated for the complex $\mathrm{PcReSO}_{4}$. PcReN (3) probably decomposes, forming undefined products with the strong acid employed for purification.

The UV/Vis spectrum of $\mathbf{3}$ in the solid state shows only a poor resolution in comparison with 2 but with the same structure of the $\mathrm{Q}$ band with a maximum at $656 \mathrm{~nm}$ and two shoulders at 735 and $805 \mathrm{~nm}$ as reported in ref. ${ }^{[9 \mathrm{~b}]}$.
The UV/Vis spectrum of 3 can also be interpreted with the presence of dimers ${ }^{[16]}$ (bands at 656 and $805 \mathrm{~nm}$ ) with an exciton coupling of about $150 \mathrm{~nm}$ and monomers (band at $735 \mathrm{~nm}$ ) as in the case of 2 . But in contrast to 2 the bands representing the dimeric units in the spectrum of 3 are of higher intensity than that one of the monomer units indicating the dimers to be present in excess. This correlates with the smaller steric hindrance in 3 in contrast to the tetrasubstituted product 2 (see above).

A second optical absorption spectrum of 3 in concentrated sulfuric acid shows the $\mathrm{Q}$ band to be strongly redshifted to $\lambda_{\max }=851 \mathrm{~nm}$ which is assigned to a protonated form of 3. A UV/Vis spectrum of 3 in 1-chloronaphthalene exhibits the $Q$ band at $\lambda_{\max }=699 \mathrm{~nm}$.

In contrast to the literature ${ }^{[9]}$ we could not obtain a mass spectrum containing the molecule ion either by EI or FAB. Only peaks representing fragments such as the Pc dication $(m / z=255.2)$ or phthalodinitrile $(m / z=128.1)$ and with very low intensity PcRe $+2(\mathrm{~m} / \mathrm{z}=701.4)$ were found.

The ${ }^{13} \mathrm{C}$-CP/MAS spectrum exhibits five peaks between $\delta=122.9$ and 144.0 instead of four commonly found in the cases of other phthalocyaninato metal complexes ${ }^{[20]}$. The additional peak may be caused by solid-state effects. A NQS measurement shows the expected two signals at $\delta=$ 144.0 and 134.1 for the two quarternary carbon atoms of the macrocycle 3. Obviously, the Re- $\mathrm{N}$ triple bond has no significant effect on the solid-state NMR spectrum.

The X-ray powder diffraction pattern of PcReN (3) obtained differs partly from the one reported in ref. ${ }^{[9]}$. In our sample the peaks at $d=13.81$ and $9.48 \AA$ and two very small peaks at 4.44 and $4.40 \AA$ do not occur, whereas additional peaks at $d=3.854$ and $3.540 \AA$ (see Table 1) are detected. Up to now peaks that could be used for the calculation of the elemental cell have not been observed. Probably different crystals due to monomeric and dimeric units are responsible for this according to the results of the UV/ Vis spectra (see above). A sample of 3 was sublimed at $450^{\circ} \mathrm{C}$ at ca. $10^{-2}$ mbar and its X-ray powder pattern was measured. Herein two additional peaks at $d=3.899$ and $3.719 \AA$ appear as compared with the unsublimed sample. The peak at $d=3.514 \AA$ has disappeared. The ratio of monomeric to dimeric units of 3 may be slightly changed by sublimation which is not detected in the UV/Vis spectrum.

The specific electrical dark conductivity of $\mathbf{3}$ measured by the two-probe technique was found to be $\sigma=3 \cdot 10^{-10}$ $\mathrm{S} / \mathrm{cm}$, indicating 3 to be a poor electrical semiconductor, in agreement with the literature ${ }^{[9 a]}$.

It is well-known that doping of phthalocyaninato metal complexes with iodine often leads to a considerable enhancement of the conductivity by partial oxidation of the macrocycle and often to a structural change, e.g. of $\mathrm{PcNi}^{[21]}$, replacing a displaced columnar structure by a linear one after doping. Doping of PcReN (3) with iodine led to a conductivity of $\sigma=8 \cdot 10^{-7} \mathrm{~S} / \mathrm{cm}$. This enhancement is rather low relative to $\mathrm{PcNi}\left(\sigma=10^{-8} \mathrm{~S} / \mathrm{cm}\right)^{[22]}$ and $\operatorname{PcNiI}_{x}\left(\sigma=7 \cdot 10^{-1} \mathrm{~S} / \mathrm{cm}\right)^{[22]}$. The doped product PcReNI ${ }_{x}$ (3a) contains about $12 \%$ iodine $(x \approx 0.8)$. The IR spectrum 
Table 1. Comparison of the relative intensities of the $\mathrm{X}$-ray investigation of unsublimed PcReN (3) between $2 \Theta=5$ and $65^{\circ}$ with the literature data ${ }^{[9]}$

\begin{tabular}{ll|ll}
\hline$d[\AA]^{[\mathrm{a}]}$ & $\begin{array}{l}\text { Rel. inten- } \\
\text { sity (\%)[a] }\end{array}$ & $d[\AA]^{[9]}$ & $\begin{array}{l}\text { Rel. inten- } \\
\text { sity (\%) }\end{array}$ \\
\hline- & - & 13.81 & 33 \\
12.744 & 100.0 & 12.55 & 100 \\
- & - & 9.48 & 10 \\
8.984 & 24.0 & 8.83 & 45 \\
6.344 & 6.0 & 6.31 & 10 \\
- & - & $6.22\left[^{\text {b] }}\right.$ & 10 \\
5.669 & 23.9 & 5.61 & 44 \\
4.491 & 4.2 & 4.45 & 4 \\
- & - & 4.44 & 2 \\
- & - & 4.30 & 2 \\
4.224 & 4.8 & 4.20 & 4 \\
\hline$d[\AA]^{[\mathrm{a}]}$ & Rel. inten- & $d[\AA]^{[\mathrm{a}]}$ & Rel. inten- \\
& sity (\%) ${ }^{[\mathrm{a}]}$ & & sity (\%) \\
\hline 4.007 & 8.3 & 1.979 & 2.7 \\
3.854 & 23.0 & 1.949 & 2.2 \\
3.540 & 8.2 & 1.926 & 2.0 \\
3.514 & 8.0 & 1.884 & 1.8 \\
3.166 & 4.9 & 1.863 & 1.9 \\
3.071 & 7.1 & 1.808 & 1.6 \\
2.985 & 4.7 & 1.791 & 2.0 \\
2.831 & 4.6 & 1.769 & 1.5 \\
2.532 & 3.8 & 1.756 & 1.7 \\
2.483 & 3.4 & 1.740 & 1.6 \\
2.354 & 3.5 & 1.720 & 1.3 \\
2.241 & 2.1 & 1.662 & 1.5 \\
2.213 & 1.5 & 1.620 & 1.3 \\
2.173 & 2.1 & 1.571 & 1.5 \\
2.111 & 1.5 & 1.556 & 1.3 \\
2.083 & 2.1 & 1.536 & 1.4 \\
2.004 & 2.0 & 1.483 & 1.1 \\
\hline & & &
\end{tabular}

[a] Data of unsublimed PcReN (3); this work. - ${ }^{[b]}$ This peak is listed in the Table in ref. ${ }^{[9]}$ but not found in the spectrum.

of $\mathbf{3 a}$ is nearly the same as that of $\mathbf{3}$ besides a slight broadening of the bands.

A resonance Raman spectrum of $\mathbf{3} \mathbf{a}$ exhibits two peaks with high intensity at 160 and $106 \mathrm{~cm}^{-1}$ which are characteristic of $\mathrm{I}_{5}{ }^{-}$and $\mathrm{I}_{3}{ }^{-[22]}$, respectively. The first one has a higher intensity than the second one. In contrast, in a corresponding spectrum of $\mathrm{PcNiI}_{x}$, normally only one peak is found in this region representing $\mathrm{I}_{3}{ }^{-}$. If we assume also a linear structure for $\mathrm{PcReNI}_{x}(3 \mathrm{a})$ as for $\mathrm{PcNiI}_{x}$ the higher portion of $\mathrm{I}_{5}{ }^{-}$in $\mathbf{3 a}$ would indicate a larger distance between neighboring macrocyclic units relative to the nickel compound because $\mathrm{I}_{5}^{-}$requires more space than $\mathrm{I}_{3}^{-}$. This is in agreement with the lower increase of the conductivity after doping of PcReN (3) with iodine in comparison with $\mathrm{PcNi}$ (see above). The UV/Vis spectrum of $3 \mathbf{a}$ in nujol is quite the same as that of 3 besides the fact that the $Q$ band of the monomer units at $717 \mathrm{~nm}$ is about $20 \mathrm{~nm}$ blue-shifted compared to 3 and exibits the highest absorption in the $Q$ band region. It is assumed that the $\mathrm{I}_{3}{ }^{-}$and the $\mathrm{I}_{5}{ }^{-}$ions increase the portion of the monomeric compared with the dimeric units due to their higher spatial requirement.

We thank Prof. H. Homborg, Institut für Anorganische Chemie, Universität Kiel, for measuring the resonance Raman spectra and helpful informations about PcReN, Mr. W. Weber, Institut für Anorganische Chemie, Universität Tübingen, for carrying out the X-ray powder diffraction measurements, and Mr. K. Dürr for the electrochemical investigations.

\section{Experimental}

4-tert-Butylphthalodinitrile (1) was prepared according to ref. ${ }^{[15,23]}$. $\mathrm{NH}_{4} \mathrm{ReO}_{4}$ was prepared from $\mathrm{Re}$ metal ${ }^{[24]}$ which was a gift of Degussa $A G$. The solvents were purified according to known procedures.

FT-IR: Bruker IFS 48. - UV/Vis: Shimadzu UV-365. - MS: Varian Mat 711 (EI, FD). $-{ }^{1} \mathrm{H},{ }^{13} \mathrm{C}$ NMR: Bruker AC $250\left({ }^{1} \mathrm{H}\right.$ : $\left.250.133 \mathrm{MHz},{ }^{13} \mathrm{C}: 62.902\right) .-{ }^{13} \mathrm{C}$ NMR CP/MAS: Bruker MSL 200 (50.325 MHz). - Elemental Analyses: Carlo Erba Elemental Analyser 1104, 1106. - X-ray powder diffraction: Siemens diffractometer D5000, Ge-monochromator, Cu- $K_{a}(1.5406 \AA)$, scintillation detector. - Resonance Raman: ISA U1000, Spectra Physics $\mathrm{Ar}^{+}$Laser. - CV: EG \& G Potentiostat/Galvanostat PAR 273; SEC: Shimadzu spectrometer UV-365, Jaissle Potentiostat/Galvanostat 1001 T-NC, OTTLE cell.

Nitrido(tetra-tert-butylphthalocyaninato) rhenium $(V),(t B u)_{4} P c R e N$ (2): In a septum vial $\mathrm{NH}_{4} \mathrm{ReO}_{4}(268 \mathrm{mg}, 1.0 \mathrm{mmol})$ and 4-tertbutylphthalodinitrile (1) $(921 \mathrm{mg}, 5.0 \mathrm{mmol})$ were melt at $290^{\circ} \mathrm{C}$ and held at this temp. for $45 \mathrm{~min}$. After cooling the dark blue reaction mixture was crushed in a mortar. The product was first chromatographed on $\mathrm{Al}_{2} \mathrm{O}_{3}$ (neutral, 10\% water) with toluene as eluent to remove large amounts of impurities, then with ether to remove excess dinitrile and again twice with toluene. $55 \mathrm{mg}(6 \%)$ of a blue green powder was obtained. - IR $(\mathrm{KBr}): \tilde{\mathrm{v}}=3080 \mathrm{~cm}^{-1}$ $\left(\mathrm{C}-\mathrm{H}_{\text {arom }}\right), 2903,2866\left(\mathrm{C}-\mathrm{H}_{\text {aliph. }}\right), 1614,1483,1394,1364,1331$, $1281,1258,1200,1024,1051,1090,1109,1149,978(\mathrm{Re} \equiv \mathrm{N}), 933$, $895,874,856,829,768,754,694,671$. - UV/Vis $\left(\mathrm{CH}_{2} \mathrm{Cl}_{2}\right): \lambda_{\max }$ $(\lg \varepsilon)=278 \mathrm{~nm}$ (4.811), 300 (4.624), 346 (5.000), 363 (5.099), 584 (3.923), 603 (4.099), 628 (4.775), 667 (4.701), 698 (5.553); (nujol): $\lambda_{\max }=276 \mathrm{~nm}, 352,375,669,697,750 .-$ MS (FD), $m / z(\%):$ $937.4(100)\left[\mathrm{M}^{+}\right] .-{ }^{1} \mathrm{H}$ NMR $\left(\mathrm{CDCl}_{3}\right): \delta=1.82-1.83(36 \mathrm{H}, t \mathrm{Bu})$, $8.36-8.41\left(4 \mathrm{H}_{\text {arom. }}, 1-\mathrm{H}\right), 9.41-9.50\left(4 \mathrm{H}_{\text {arom. }}, 2-\mathrm{H}\right), 9.54-9.58$ $\left(4 \mathrm{H}_{\text {arom. }}, 2^{\prime}-\mathrm{H}\right) .-{ }^{13} \mathrm{C}$ NMR $\left(\mathrm{CDCl}_{3}\right): \delta=32.08-32.11\left(\mathrm{CH}_{3}\right)$, $36.22-36.23\left(\mathrm{CMe}_{3}\right), 119.17-119.55\left(\mathrm{C}-2^{\prime}\right), 122.67-123.03(\mathrm{C}-2)$, 128.65-128.59 (C-1), 134.57-134.93 (C-3), 136.85-137.41 (C-3'), $148.13-148.59,148.82-148.94\left(\mathrm{C}-4,4^{\prime}\right), 154.42-154.67\left(\mathrm{C}-1^{\prime}\right)$. $\mathrm{C}_{48} \mathrm{H}_{48} \mathrm{~N}_{9} \operatorname{Re}(937.4)$ : calcd. C 61.52, H 5.16, N 13.45; found $\mathrm{C}$ 61.36, H 5.26, N 13.07.

Nitrido (phthalocyaninato) rhenium(V), $P c \operatorname{ReN}(3)^{[9]}$ : In an analogous way as for $2, \mathrm{NH}_{4} \mathrm{ReO}_{4}(268 \mathrm{mg}, 1.0 \mathrm{mmol})$ and phthalodinitrile $(1.28 \mathrm{~g}, 10 \mathrm{mmol})$ were allowed to react. After cooling the dark blue-green reaction mixture was crushed in a mortar and extracted in a Soxhlet with water, ethanol, and acetone for $4 \mathrm{~d}$ to remove unreacted rhenium salt and phthalodinitrile; yield of 3: 592 mg $(83 \%),-$ IR $(\mathrm{KBr}): \tilde{v}=978 \mathrm{~cm}^{-1}(\mathrm{Re} \equiv \mathrm{N}) .-{ }^{13} \mathrm{C} \mathrm{CP} / \mathrm{MAS}$ : $\delta=122.9,128.3,130.9,133.7,144.1$. - UV/Vis (nujol): $\lambda_{\max }=270$ $\mathrm{nm}, 352,366,656,735,805 ;\left(\mathrm{H}_{2} \mathrm{SO}_{4}\right): \lambda_{\max }(\mathrm{lg} \varepsilon)=208(4.639)$, 232 (4.569), 262 (4.453), 316 (4.622), 436 (4.480), 461 (4.460), 693 (3.969), 728 (4.291), 755 (4.494), 820 (4.835), 851 (5.171); (1-chloronaphthalene): $\lambda_{\max }(\lg \varepsilon)=361(4.173), 430(3.753), 459(3.663)$, 487 (3.441), $586(3.760), 607$ (3.953), 631 (4.130), $666(4.159), 699$ (4.676). - MS (EI, $70 \mathrm{eV}), m / z(\%): 701.4[\mathrm{PcRe}+2](0.2), 383.3$ $\left[\left\{\mathrm{C}_{6} \mathrm{H}_{4}(\mathrm{CN})_{2}\right\}_{3}-1\right](12), 255.2\left[\mathrm{Pc}^{2+}\right](5), 147.1\left[\mathrm{C}_{6} \mathrm{H}_{4} \mathrm{CN}\left(\mathrm{CO}_{2} \mathrm{H}\right)\right]$ (77), $128.1\left[\mathrm{C}_{6} \mathrm{H}_{4}(\mathrm{CN})_{2}\right](84), 103.7\left[\mathrm{C}_{6} \mathrm{H}_{4} \mathrm{CO}\right](100), 75.6\left[\mathrm{C}_{6} \mathrm{H}_{4}\right]$ (47), $43.9\left[\mathrm{CO}_{2}\right]$ (34). - Conductivity: $\sigma=3 \cdot 10^{-10} \mathrm{~S} / \mathrm{cm}$. $\mathrm{C}_{32} \mathrm{H}_{16} \mathrm{~N}_{9} \mathrm{Re}(712.7)$ : calcd. C 53.92, H 2.24, N 17.69; found $\mathrm{C}$ $53.39, \mathrm{H} 2.26, \mathrm{~N} 17.37$.

Doping of $3^{[21]}$ : PcReN (3) (107 mg, $\left.0.15 \mathrm{mmol}\right)$ was thoroughly pulverized with $\mathrm{I}_{2}(76 \mathrm{mg}, 0.30 \mathrm{mmol})$ and a few drops of benzene for about $15 \mathrm{~min}$. The benzene and excess iodine were removed in vacuo to yield $90 \mathrm{mg}$ of $\mathrm{PcReNI}_{x}$ (3a) as a dark green powder. IR $(\mathrm{KBr}): \tilde{v}=976 \mathrm{~cm}^{-1}(\operatorname{Re} \equiv \mathrm{N})$. - Resonance Raman $(\mathrm{KBr}): \tilde{v}=$ 
$160 \mathrm{~cm}^{-1}\left(\mathrm{I}_{5}{ }^{-}\right), 106\left(\mathrm{I}_{3}{ }^{-}\right) .-$UV/Vis (nujol): $\lambda=275 \mathrm{~nm}, 350,368$ $660,717,801$. - Conductivity: $\sigma=8 \cdot 10^{-7} \mathrm{~S} / \mathrm{cm}$. $\mathrm{C}_{32} \mathrm{H}_{16} \mathrm{~N}_{9} \mathrm{ReI}_{0.77}$ (810.5): calcd. C 47.42, H 1.99, I 12.06, N 15.55; found C 45.51, H 2.04, I 12.02, N 14.89.

[i] H. Schultz, H. Lehmann, M. Rein, M. Hanack in Structure and Bonding 74, Springer, Heidelberg, 1991, p. 41-146.

[2] W. Hiller, J. Strähle, A. Datz, M. Hanack, W. E. Hatfield, L. W. ter Haar, P. Gütlich, J. Am. Chem. Soc. 1984, 106, 329-335.

[3] [3a] C. Ercolani, M. Gardini, F. Monacelli, G. Pennesi, G. Rossi, Inorg. Chem. 1983, 22, 2584-2589. - ${ }^{[3 \mathrm{~b}]}$ R. Dieing, G. Schmid, E. Witke, C. Feucht, M. Dreßen, J. Pohmer, M. Hanack, Inorg. Chem., in press.

[4] [4a] K. Dehnicke, J. Strähle, Angew. Chem. 1981, 93, 451-464; Angew. Chem. Int. Ed. Engl. 1981, 20,413. - [4b] K. Dehnicke, J. Strähle, Angew. Chem. 1992, 104, 978-1000; Angew. Chem. Int. Ed. Engl. 1992, 31, 955.

[5] J. W. Buchler, C. Dreher, K. L. Lay, Z. Naturforsch., B: Anorg. Chem., Org. Chem. 1982, 37, 1155-1162.

[6] J. W. Buchler, A. De Cian, J. Fischer, S. B. Kruppa, R. Weiss, Chem. Ber. 1990, 123, 2247-2253.

[7] H. Grunewald, H. Homborg, Z. Naturforsch., B: Chem. Sci. $1990,45,483-489$.

[8] S. Rummel, M. Hermann, K. Schmidt, Z. Chem. 1985, 25, $152-153$

[9] [9a] A. Mrwa, S. Rummel, M. Starke, Z. Chem. 1985, 5, 186-187. - ${ }^{[9 b]}$ A. Mrwa, H. Giegenhack, M. Starke, Cryst. Res. Technol. 1988, 23, 773-778.

[10] [10a] V. L. Goedken, C. Ercolani, J. Chem. Soc., Chem. Commun.
1984, 378-379, - ${ }^{110 \mathrm{~b}]}$ L. A. Bottomley, J.N. Gorce V. L. Goedken, C. Ercolani, Inorg. Chem. 1985, 24, 3733-3737. ${ }^{[10 c]}$ B. J. Kennedy, K. S. Murray, H. Homborg, W. Kalz, Inorg. Chim. Acta 1987, 134, 19-21.

[11] G. Rossi, M. Gardini, G. Pennesi, C. Ercolani, V. L. Goedken, J. Chem. Soc., Dalton Trans. 1989, 193-195.

[12] W. O. Davies, N. P. Johnson, P. Johnson, A. J. Graham, Chem. Commun. 1969, 736-737.

[13] J. Metz, Dissertation, Universität Tübingen, 1983.

[14] [14a] J. Metz, O. Schneider, M. Hanack, Inorg. Chem. 1984, 23 , 1065-1071. - [14b] J. Rauschnabel, Diplomarbeit, Universität Tübingen, 1992.

${ }^{[15]}$ S. A. Mikhalenko, S. V. Barkanova, O. L. Lebedev, E. A. Luk'yanets, Zh. Obshch. Khim 1971, 41, 2735-2739; J. Gen. Chem. USSR 1971, 41, 2770-2773.

[16] E. A. Lucia, F. D. Verderame, J. Chem. Phys. 1970, 52, $2307-2310$

${ }^{[17]}$ M. Hanack, D. Meng, A. Beck, M. Sommerauer, L. R. Subramanian, J. Chem. Soc. Chem. Commun. 1993, 1, 58-60.

${ }^{[18]}$ G. Pfrepper, Z. Chem. 1970, 10, 76.

${ }^{[19]}$ B. I. Knudsen, Acta Chem. Scand. 1966, 20, 1344- 1350.

[20] P. J. Toscano, T. J. Marks, J. Am. Chem. Soc. 1986, 108 , 437-444

[21] U. Keppeler, O. Schneider, W. Stöffler, M. Hanack, Tetrahedron Lett. 1984, 25, 3679-3682.

[22] C. J. Schramm, R. P. Scaringe, D. R. Stojakovic, B. M Hoffmann, J. A. Ibers, T. J. Marks, J. Am. Chem. Soc. 1980, $102,6702-6713$.

${ }^{[23]}$ B. W. Larner, A. T. Peters, J. Chem. Soc. 1952, 680-686.

${ }^{[24]}$ L. S. Crocker, G. L. Gould, D. M. Heinekey, J. Organomet. Chem. 1988, 342, 243-244.

[80/94] 